\title{
Corrigendum: Paediatric doctors' error rate in detection of paediatric elbow injuries in Rahima Moosa Mother and Child Hospital
}

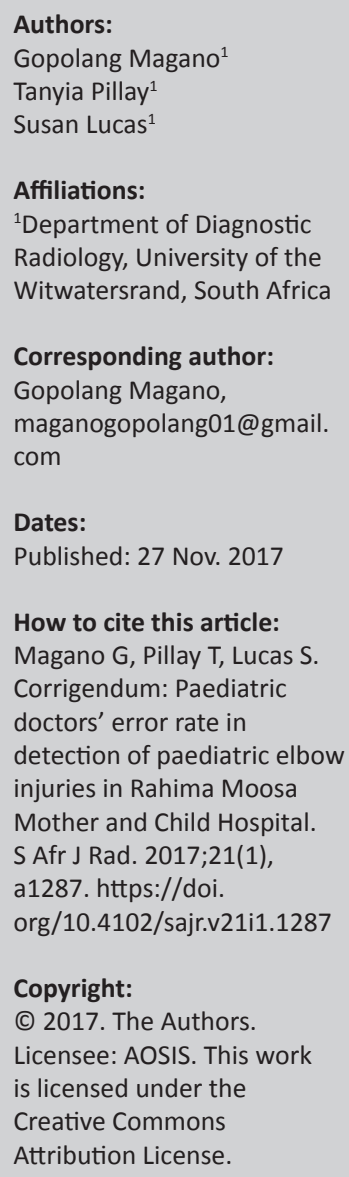

\section{Copyright:}

C 2017. The Authors. Licensee: AOSIS. This work

is licensed under the

Creative Commons

Attribution License.

In the version of this article initially published, Susan Lucas's last name was misspelled as 'Lucus'. The error has been corrected in the PDF version of the article. 